\title{
African swine fever in Russian federation current epizootic situation and control
}

\begin{abstract}
A brief interpretation of the natural history and value of the African swine fever (ASF) at the actual stage is given. Epidemic dynamics of the emergence and spread of the disease in 2007-2017 in the Russian Federation, its emergence out of the country to the territory of neighboring countries including the EU countries are described. The references to the normative documents regulating the control of the ASF in the Russian Federation are given. African swine fever (ASF) concerns of the most important trans boundary infections with catastrophic potential. This is one of the most serious epidemic problems due to the ability to emergence and spread widely in the most unexpected regions of the world as well as extremely large direct damage (high lethality of susceptible animals), costs of various restrictive measures and eradication and the impossibility of specific prevention. The disease has been known since the beginning of the 20th century from the first attempts to introduce pigs of cultivated species into the colonial countries of subequatorial and southern Africa. At the first stage of natural history prior to export to Portugal (1957) and Spain (1960) ASF had a stereotype of a typical transmissive natural focal exotic disease with natural circulation of the virus in populations of wild African swine, intra family transmission and the course of a persistent tolerant infection. When the first cases occurred among domestic (non native-born) pigs the disease acquired an acute course with a mortality rate of up to $100 \%$. Later ASF evolved towards an independent anthropurgic cycle with rooting in the southern European countries and a two-fold emergent traffic to the countries of Central and South America (1971 and 1978-1980), a sharp decrease in mortality and a predominance of unclinical forms of course of the disease. ${ }^{1,2}$
\end{abstract}

Volume 2 Issue 4 - 2017

\author{
Makarov VV \\ People's Friendship University of Russian, Russia
}

Correspondence: Makarov VV, People's Friendship University of Russian, Russia, Email vvm-39@mail.ru

Received: December 02, 2017 | Published: December 20, 2017

\section{Introduction}

Distribution of ASF in the second half of the 1970's had a global character with all the signs of a pandemic. The epidemic situation in the traditional nosoareal of sub-Saharan Africa remained at the level of hyperendemia. In addition to the endemic zone of the Iberian Peninsula with increasing hazards the emergent unfavorable appeared Cuba (1971, 1980), the USSR (1977), Italy, (1978), Malta (19781979), Haiti, Brazil (1978-1984) and France (1984), Belgium (1985), Netherlands (1986). As a result of unprecedented measures taken by the national veterinary services, international organizations and funds of the European Union and Central American countries the outbreaks, epidemics, and endemics of ASF in these regions were eliminated through the application of severe radical tactics (total systematic monitoring, stamping out to depopulation on a national scale). Especially defiantly is the success of the rapid eradication of ASF in both cases in Cuba, in three regions of the USSR, as well as the practical rehabilitation of Spain and Portugal after half a century of disaster (in 1985-1995) with high epidemic and economic efficiency. To the beginning of the 21 th century ASF remained endemic for the subequatorial part of the African continent and probably "returned" to its original natural-focal exotic stereotype. The disease was occasionally recorded in the form of outbreaks of various scales mainly in the West African region (Republic of Côte d'Ivoire, Togo, Benin, Nigeria, Congo). Outside Africa the endemic remained only in Italy (Sardinia) where ASF rooted in populations of wild boars.,3

However in the spring of 2007 ASF unexpectedly appeared in Georgia. The OIE Reference Laboratory (Pirbright, Great Britain) detected a rare genotype II virus isolated from the pathologic material obtained in these cases using the gold standard (virus isolation in cell culture, ELISA, PCR). This genotype of the ASF virus was registered in 1993-2002 years in the eastern regions of South Africa (Mozambique, Zambia, Madagascar). The disease spread throughout the country and in the form of epidemic outbreaks in neighboring countries and regions (Armenia, Azerbaijan, Abkhazia, Nagornyy Karabakh, northern Iran). This confirmed the exceptional importance of the disease at the current stage. ${ }^{4}$ The episodic occurrence of new outbreaks of ASF in endemic Africa is predictable in principle. But such geographic "jump" of the disease into the Black Sea-Transcaucasian region has shocked international organizations. For less than one year this is the second unprecedented occurrence of exotic emergent infections in the northern hemisphere after bluetongue epidemics that have occurred in the Netherlands since August 2006. From the territory of Georgia ASF was permeated in the Russian Federation (Chechnya, North Ossetia) and in 2007-2008 spread in the North Caucasus region of the country. Then came an intensive progressive epidemic spread in the European part of the Russian Federation involving domestic pigs and wild boars. As a result a large scale endemic has formed with the formation of massive permanently unfavorable clusters in the southern, western and central federal districts (since 2012).

The incidence of domestic pigs in farms of all categories and forms of ownership appeared mainly exogenously. The epizootic process had the character of a kind of quanta i.e. sporadic outbreaks of different intensity without the "proven" evident trivial epidemic communications between the independent incidents. This was due to unintentional or counterfeit unpredictable drift of infection from outside with contaminated objects (symptomless infected pigs, products of pork origin, transport, food waste). Later the incidence 
progressively concentrates among wild boars. ${ }^{4,5}$ This is largely promoted by climatic geographic and socio-economic characteristics of unfavorable areas with an abnormally high population density of these animals as well as mainly fixed hunting grounds and widely developed network of the private hunting and nature protection organizations supporting their life supply and reproduction artificially often illegitimate.

In 2012-2013 not exogenous but the indigenous incidence of wild boars irradiated in all directions especially in the western and northwestern directions (Smolensk, Pskov, Novgorod as well as Yaroslavl, Moscow, Ivanovo, Vladimir regions) and exceeded that domestic pigs. In 2013-2014 the incidence of wild boar has shifted to the south-west of the center of the country (Bryansk, Orel, Kaluga, Tula regions) and further to the neighboring countries of Eastern Europe (Belarus, Poland, the Baltic States, Ukraine) following the gradient of population density in the western direction.

Judging by the intensity of registration of ASF among wild boars (localization, chronology, sequence of outbreaks) it can be assumed that the center of the European part of the Russian Federation formed a natural focus of infection as a new bioecological phenomenon in the country in full accordance with the canons of E. Pavlovsky's (1938) with real typological and topological characteristics and with the parasitic system "wild boars+ASF virus" of closed, binomial, simple type with the western vector of its possible preferential development. ${ }^{6}$ For a ten-year period of unfavorable the ASF has spread in 40 administrative regions of the Russian Federation. Over 1200 epidemic outbreaks were recorded among domestic pigs and wild boars at a ratio of 1.5 to 1 with losses amounting to more than a million animals. In 2016-2017 the continuing increase in the intensity of the situation was characterized by the formation of large geographically dispersed epidemic clusters with the registration of dozens of outbreaks (from 5-10 to 40 and more) among domestic pigs and wild boars in the center of the country (Moscow, Ryazan, Ivanovo, Vladimir, Nizhny Novgorod regions) and the Volga region (Volgograd, Saratov and neighboring areas). ASF penetrated in three regions of Siberia (Irkutsk, Omsk, Krasnoyarsk regions). ${ }^{5,6}$

Since the first cases of ASF in neighboring Western countries from 2013 to the present time there have been more than 5,500 epizootic outbreaks. In the Baltics and Poland the vast majority of cases were among wild boars, in Ukraine among domestic pigs and wild boars. Especially intensive epidemic situation continue to persist in Estonia, Latvia, Lithuania where already there are alarming signs of the evolution of the infection in the direction of decreasing mortality and chronization i.e. the main mechanism of territorial rooting and persistence of ASF. In 2016-2017 continued shifting incidence in a western direction to the EU territory. ASF is registered in Moldova, Romania and the Czech Republic which indicates the extremely threatened nature of the Western vector of spatial invasion for Western European countries..$^{5-7}$ The control ASF in the Russian Federation is regulated by the new "Veterinary rules for the implementation of preventive, diagnostic, restrictive and other measures, the establishment and abolition of quarantine and other restrictions aimed at preventing the spread and elimination of foci of African swine fever", approved by the RF Ministry of Agriculture Decree of May 31,2016 . The rules provide for activities in both domestic pigs and in populations of wild boars. ${ }^{8}$ According to the "Action plan to prevent the introduction of African swine fever into the territory of the Russian Federation and its spread in the territory of the Russian Federation" approved by the Government of the Russian Federation in 2016 the ASF is expected to be eradicate in $2020 .{ }^{9}$

\section{Acknowledgements}

None.

\section{Conflict of interest}

The author declares no conflict of interest.

\section{References}

1. Montgomery R. On a form of swine fever occurring in British East Africa. J Comp Pathol. 1921;34:159-191.

2. Makarov VV. African swine fever; 2012.

3. Makarov VV, Gruby VA. Epizootic situations and control of African swine fever. Bulletin of the Rosselkhozakademii. 2013;3:68-70.

4. WAHID Interface; 2017.

5. African swine fever. Rosselkhoznadzor; 2017.

6. Makarov VV, Igolkin AS, Boev BV. On some aspects of the current epizootology of African swine fever. Herald of Hunting. 2015;1:61-65.

7. $11^{\text {th }}$ EPIZONE annual meeting welcome in Paris by ANSES; 2017.

8. Veterinary rules for the implementation of preventive, diagnostic, restrictive and other measures, the establishment and abolition of quarantine and other restrictions aimed at preventing the spread and elimination of foci of African swine fever; 2017.

9. An action plan to prevent the introduction of African swine fever into the territory of the Russian Federation and its spread in the territory of the Russian Federation; 2017. 